\title{
The Emergence of a Price System from Decentralized Bilateral Exchange
}

\author{
Herbert Gintis*
}

September 8, 2006

\begin{abstract}
This paper analyzes the dynamics of completely decentralized bilateral exchange. In such a framework, neither money nor prices as public information exist. Rather, prices represent an agent's barter strategy, and hence are private information. We call these private prices. Agents formulate trade offers and accept or reject offers from other traders, on the basis of their private prices. Private prices are updated by low-scoring agents periodically imitating the strategies of higher-scoring agents. We show that a system of quasi-public prices emerges in the medium run, and these quasi-public prices converge to stationary distributions that are approximately competitive equilibria of the underlying Walrasian model in the long run. We thus provide, for the first time, a general, decentralized disequilibrium adjustment mechanism that renders market equilibrium dynamically stable in a highly simplified production and exchange economy.
\end{abstract}

Journal of Economic Literature Classifications:

D51-Exchange and Production Economies

D58 - Computable and Other Applied General Equilibrium Economies

D82-Asymmetric and Private Information

*I would like to thank the John D. and Catherine T. MacArthur Foundation for financial support. The computer algorithms used in this paper are available from the author. Affiliations: Santa Fe Institute and Central European University 


\section{Introduction}

This paper studies an economy in which agents produce, exchange, and consume a number of goods in each of many periods. Rather than using analytically tractable but empirically implausible adjustment mechanisms and informational assumptions (such as Walrasian tâtonnement and prices as public information), we treat the economy as complex system in which agents have extremely limited information, there is no aggregate price-adjustment mechanism institution, and out of equilibrium exchange occurs in every period.

The behavior of this economy can be studied through agent-based modeling. An agent-based model is a computer simulation of the repeated play of a game in which a large number of agents are endowed with software encoded strategies governing both how they play the game and how they gather information and update their behavior. The disequilibrium behavior of agents in our agent-based models is governed by a replicator dynamic (Taylor and Jonker 1978) in which, over time, successful agents tend in Darwinian fashion to increase in frequency at the expense of unsuccessful agents. We describe the process of shifting from lower to higher payoff strategies as "imitation." Agent-based modeling is effective in solving problems involving complex nonlinear dynamics that cannot be handled through analytical optimization techniques (Goldberg 1989, Holland 1975, Tesfatsion and Judd 2006).

We assume that each agent has a barter strategy consisting of a vector of reservation values, one for each good, and the resulting distribution of private prices moves through time according to an adaptive evolutionary dynamic in which the strategies of high-scoring agents is imitated by low-scoring agents. We show that from an initial randomly seeded distribution of private prices among agents, the economy evolves rapidly towards what may be termed a quasi-public price structure, in that the variance of private prices across agents becomes relatively small and mean prices change slowly from period to period. In the long run, this quasi-public price structure evolves toward the market clearing price system for the underlying general equilibrium system. Thus, the economy enjoys dynamic stability, which is not the case for the tâtonnement adjustment processes studied by Walras and his followers in modern general equilibrium theory (Saari 1985,1995).

The economy begins each period with a synchronized production phase, in which each agent has an empty inventory of goods and produces a fixed amount of a single good. This is followed by an unsychronized exchange-consumptionproduction phase, in which agents seek exchange partners. an agent consumes following trade when he has an optimal consumption bundle, and replace his inventory of his production good when his stock has become exhausted. After a certain number of periods, generally twenty in our simulations, there is a reproduction-mutuation phase in which a fraction (2\%) of low scoring agents imitate the strategies (the private 
prices) of high-scoring agents, and each strategy undergoes a small mutation (5\%) with a small probability (1\%). The cycle of production, exchange-consumptionproduction, and reproduction-mutation is repeated for a fixed but generally very large number of periods.

A strategy for an agent is a price vector for the various goods he produces or consumes. We assume an agent will only give a quantity of his production good in exchange for a quantity of the production good of his exchange partner, and an agent will agree to an exchange only if the value of what he receives in an exchange is at least as great as the value of what he gives in exchange, according to his private price vector. $^{1}$

Learning in this economy occurs only during a reproduction-mutation period, and takes the form of a small subset of agents each observing a single other agent, and switching to the strategy of the other agent if he is doing better with a probability that is increasing in the difference between the payoffs. This is a monotone dynamic, which is equivalent in its dynamical properties to the famous replicator dynamic (Taylor and Jonker 1978, Samuelson and Zhang 1992), ensuring that the system of private prices therefore follows an evolutionary adaptive dynamic. The reproduction algorithm in fact implements the replicator dynamic, although results are the same when the "observing and switching" algorithm is used.

Agents in this economy have no knowledge of excess demand or supply for any good. Nor is there an 'auctioneer' (Walras 1954 [1874]) calling out prices, collecting information concerning aggregate demand, and dynamically 'correcting' the price structure, with the aim of moving the system towards market clearing. The only aggregate institution in this economy is a "market" for each good where an agent can be certain of finding all, and only, producers of that good. Moreover, the this institution can obviously be dropped, at the expense of slowing considerably the process of moving to an equilibrium in the economy.

\section{General Equilibrium Theory}

The Walrasian general equilibrium model is an idealized version of a modern market economy, with consumers who own factors of production, firms that hire these factors of production and produce consumer goods. All agents (consumers and firms) face a common set of prices, and maximize subject to these prices. Equilibrium prices are defined as a those that lead to zero excess demand for all goods and all factors of production. Well-known theorems assert the existence of such an equilibrium price vector under appropriate conditions (Arrow 1951, Arrow and

\footnotetext{
${ }^{1}$ Allowing agents to barter all goods considerably complicates the barter algorithm, and gives rise to such phenomena as the emergence of money-goods, but does not change the outcome (Gintis 1997).
} 
The Price System

Debreu 1954, Debreu 1959).

Walras (1954 [1874]) described market clearing as effected by a central authority who calls out a set of prices, determines excess demand at these prices, and adjusts the prices towards their equilibrium values. We now know that the implied dynamic in a pure consumption economy is generally unstable, and even chaotic (Fisher 1983, Saari 1985, Saari 1995, Bala and Majumdar 1992). Moreover, the Walrasian tâtonnement mechanism lacks any counterpart in actual market economies, and violates the spirit of decentralized exchange on which the general equilibrium model is based. Since no decentralized out-of-equilibrium adjustment mechanism has been discovered, we currently have no acceptable dynamical model of the Walrasian system.

Using the technique of agent-based modeling, however, Gintis (2006) has shown that under plausible conditions, the Walrasian economy has a unique, stable steady state in which the economy is reasonably close to Pareto efficient. Moreover, the stability of the system depends on the fact that prices are private: if even a fraction of agents share the same price system and update as suggested by the tâtonnement mechanism, the price system becomes highly volatile.

The Walrasian model abstracts from some, but not all, institutional detail. There remain at least firms, which require a legal system to specify admissible ownership and liability forms, and money, which implies a monetary authority. This paper studies a much simpler form of economic organization, in which there are only individuals who produce in isolation and engage in various bilateral barter exchanges to obtain what they consume. I call this a barter economy.

There has been virtually no work on the dynamics of the barter economy, although existence and uniqueness have been studied. Rubinstein and Wolinsky (1985) assume two types of trader, one with endowment $(1,0)$, the other with endowment $(0,1)$. Each seller wants one unit of the other good. In each time period $t=0,1, \ldots$, an agent of type 1 (resp. 2) who has no trading partner meets a partner with probability $\alpha$ (resp. $\beta$ ), which are functions of the relative sizes $N_{1}$ and $N_{2}$ of the two types. Agents bargain using the Rubinstein bargaining model (Rubinstein 1982). Agents who complete a trade leave the market and are replaced by new traders, so there are a countable infinity of traders. A market equilibrium is defined as a situation in which all agents of the same type use the same strategy, and each strategy is a best response to the other. They find a unique equilibrium in which agreement is immediate, with the share of each player a function of $\alpha, \beta$, and the discount factor $\delta$. Moreover that show that the limit of player 1's share as $\delta \rightarrow 1$ is $N_{2} /\left(N_{1}+N_{2}\right)$. The Walrasian outcome is of course that if $N_{2}>N_{1}$, then player 1 should appropriate the whole surplus. Rubinstein and Wolinsky thus show that the Walrasian equilibrium need not obtain in a barter economy if there are an infinite number of agents. Binmore and Herrero (1988) extend Rubinstein 
The Price System

and Wolinsky (1985) to continuous time.

Rubinstein and Wolinsky (1990) assume that there are only a finite number of agents, and find that to achieve the Walrasian equilibrium, it is sufficient to assume that agents cannot condition their behavior on their previous histories with other agents. If conditioning on history is possible, other equilibria exist. In this model, there are $S$ identical sellers and $B$ identical buyers, where $S<B$. Each seller has one unit of a good, and each buyer wants one unit. The competitive solution is where all sellers sell to some buyer for price 1 . The paper's noncompetitive equilibria are gotten by "privileging" a subset of $S$ buyers and creating incentives so only trades between sellers and this subset of buyers are carried out.

Gale (1986) assumes a finite number of divisible goods, and many types of agents, who trade as often and with as many partners as they like. They leave the market when it is optimal to do so, and new traders enter to take their place. Consumption takes place when an agent leaves the market. When a pair of agents meet, one is randomly chosen to be proposer, and Rubinstein bargaining ensues. Gale shows that any perfect equilibrium of this economy is Walrasian. McLennan and Sonnenschein (1991) and Kunimoto and Serrano (2002) generalize Gale (1986).

In sum, the current state of knowledge for the barter economy is much like that of the Walrasian economy: under plausible conditions there exists a Nash equilibrium that clears markets, but the dynamical properties of the barter economy are unknown.

\section{The Structure of a Barter Economy}

We assume there are $n$ goods and $N \gg n$ agents. Each agent consumes all $n$ goods in fixed proportions $\left(o_{1}, \ldots, o_{n}\right)$, where $o_{i}>0, \forall i$, so the utility function is given by $^{2}$

$$
u\left(x_{1}, \ldots, x_{n}\right)=\min _{j} \frac{x_{j}}{o_{j}} .
$$

Each agent produces one good, and we identify the type of an agent by the good he produces. There are equal numbers of each type of producer (we allow variable sector size in Section 7.

At the start of the simulation, each agent is randomly assigned prices for each good drawn from the uniform distribution on $(0,1)$, and the "Score" of each agent is set to zero. The following sequence of events constitute a period, and are repeated throughout the course of the simulation.

\footnotetext{
${ }^{2}$ The dynamical properties of the system do not depend on the choice of homogeneous utility functions or the assumption that all agents consume all goods. However, our assumptions ensure that market-clearing prices can be calculated.
} 


\subsection{Production}

Each agent produces the appropriate amount of his production good (see below), and his inventory of other goods is set to zero.

\subsection{Exchange-Consumption-Production}

If agent $i$ produces good $g$, has private prices $p_{i}=\left(p_{i 1}, \ldots, p_{i n}\right)$ and has an inventory $x^{o}=\left(x_{i 1}^{o}, \ldots, x_{i n}^{o}\right)$ he maximizes utility subject to the income constraint

$$
M^{o} \equiv \sum_{j} p_{i j} x_{i j}^{o}=\sum_{j} p_{i j} x_{i j}
$$

The optimum is given by

$$
x_{i j}^{*}=\lambda^{*} o_{j}
$$

where

$$
\lambda^{*}=\frac{M^{o}}{\sum_{j} p_{i j} o_{j}} .
$$

To calculate equilibrium (market-clearing) prices, suppose each agent inventory consists of $n o_{g}$ units of his production good $g$. Then, the price vector

$$
p^{*}=\left(1 / o_{1}, \ldots, 1 / o_{n}\right),
$$

together with (2) through (4), imply excess demand for each good is zero, each agent consumes a bundle equal to $\left(o_{1}, \ldots, o_{n}\right)$, and each agent has utility one.

\subsubsection{The Barter Partner Pairing Process}

In each period, each agent starts with an inventory of $n$ units of his production good. First, the $n$ goods are randomly assigned ordinal rankings from 1 to $n$. Second, the producers of good 1 are randomly assigned ordinal rankings. Third, each producer of good 1, in rank order, visits each of the other goods markets, in the same rank order, and barters with at least one, and a maximum of MaxOffers (set to five in the simulations described below) agents producing that good. The visitor is called the Offerer, and incumbent is called the Responder. After a successful trade, or when MaxOffers attempts at trade have been made, the Offerer leaves the market for the good he as just acquired (or attempted to acquire). If an exchange has taken place, at this point each trader consumes from his inventory if he possesses a positive amount of each good, but cannot otherwise dispose of inventory until the start of a new production period. The utility derived from this consumption is added to his 
"Score." An agent who completely consumes his inventory of his production good, is permitted to produce another unit instantaneously at zero cost. The Offerer then moves on to the next goods market, and proceeds in the same way until all markets have been visited.

The same process is then repeated with the second agent in the first market as Offerer, and similarly for succeeding agents in the first market.

When all agents in the first market have had a turn at being Offerer, a similar opportunity is afforded the producers of the second and succeeding goods, until the complete list of goods has been processed, with each agent having been Offerer a maximum of MaxOffers $(=5)$ times in each market other than his own. If the average number of offers for the $k$ th good is $f_{k} \geq 1$, then is clear that each producer of good $k$ will receive an average of $(n-1) f_{k}$ offers, and will himself make an average of $f_{k}$ offers for good $k$.

\subsubsection{The Barter Process}

When Offerer $i$ producing good $g$ encounters agent $j$ producing $h \neq g$, he uses (2), (3) and (4) to determine an amount $x_{i h}>0$ of good $h$ he will accept in exchange for an amount $x_{i g} \equiv p_{i g} x_{i g} / p_{i h}$ of his production good $g$. Agent $j$ refuses to trade unless $p_{j h} x_{i h} \geq p_{j g} x_{i g}$; i.e., unless he values what he receives in trade at least as much as what he gives up). If he agrees to trade, the terms of trade are set at $p_{i g} / p_{i h}$, and the Responder sets the size of the trade to be the maximum compatible with his inventory of good $h$, his demand for good $g$, and the amounts $x_{i h}$ and $x_{i g}$ that the Offerer is willing to trade.

Three alternative trading mechanisms are represented in the literature. The first reverses the roles of the Offerer and Responder. This leads to the same dynamics, so will not be discussed. The second and third, Nash bargaining and Rubinstein bargaining, are not applicable in this case, since the value of the goods to the two agents is not common knowledge, thus invalidating at least one of the Nash axioms (Pareto-optimality), and the common knowledge assumption of the Rubinstein bar-

gaining model. A review of the literature on bargaining with two-sided incomplete information yields nothing that covers the bargaining situation of this paper (Ausube, Crmton and Deneckere 2002)

\subsection{Reproduction-Mutation}

Every tenth period, a fraction (2\%) of agents of each type who have low Score discover and copy private prices of higher-Score agents. This process implements a replicator dynamic,as follows. The Score of all agents of a particular type are 
normalized proportionally so that the lowest becomes zero and the highest becomes one. Agents of this type are then repeatedly randomly addressed, and with probability one minus the agent's Score, are designated for replacement. This continues until enough replacements have been found. Then, agents who are not to be replaced are randomly addressed and an agent serves as aa replacement with a probability equal to its Score. Each agent to be replaced is then paired up with a replacement, and the former copies the latter's private prices.

After every reproduction period, every private price of every agent mutates with probability 0.01 . A mutation multiplies or divides the price by 0.95 , each with probability $1 / 2$.

At this point, unless the desired number of periods has been complete, the program return to Section 3.1 and repeats.

\section{Short-Term Convergence to Quasi-Public Prices}

The following observations flow from many runs of this simulation, each seeded with independently generated private prices, and widely varied parameters of the model - number of goods, number of agents per good, and the number of attempts to trade (MaxOffers $\geq 3$ ). We find that the economy converges rather quickly to a system of quasi-public prices, in the sense that there is a rapid decline (fewer that 2000 periods are generally required) in the standard deviation of mean relative private prices across periods, and in the standard deviation of relative private prices across individuals. This dynamic is illustrated in Figure 1, showing the first 1500 periods of a typical run of this agent-based model, assuming six goods and 100 agents per good.

\section{Long-run Movement to Market Equilibrium}

Quasi-public prices generally start far from their market equilibrium values, but approach market-clearing prices in the long run (on the order of 150,000 periods), and the economy moves even closer towards an efficient allocation. Moreover, the payoffs to the various types of producers tending to their market-clearing values as well. In this long-run state, the variance of quasi-public prices, the deviation of these prices from market-clearing levels, and the variation in payoffs to agents are driven by the mutation rate alone. 


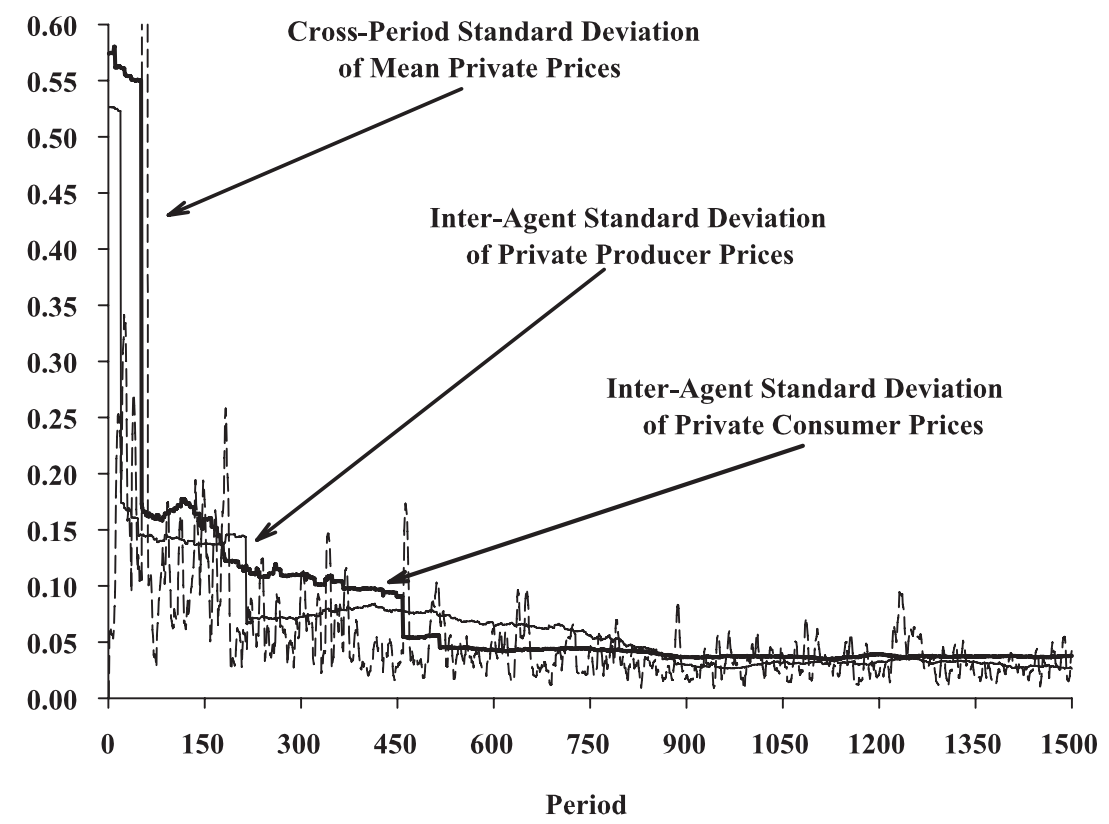

Figure 1: Short-Term Convergence of Private Prices to Quasi-Public Prices. Consumer prices are the private prices for all goods except the one produced by the agent. Producer price is the private price of the good an agent produces.

The long-term convergence of prices to quasi-equilibrium prices is illustrated in Figure 2 for a six-good economy with 100 agents per good, where $\left(o_{1}, \ldots, o_{6}\right)=$ $(1,2,3,4,5,6)$, so the equilibrium prices of the goods vary by six-fold. Figure 2 shows that the convergence of quasi-public prices to market equilibrium prices takes place over some 150,000 periods. Figure 3 shows that the payoffs to the producers of the initially underpriced goods converge to the mean over this sequence of periods.

The vertical axis in Figure 3 measures the ratio of actual optimal payoffs, assuming agents all hold the market-clearing prices. We calculate optimal payoffs by assuming all agents' private prices equal the Walrasian market-clearing prices (5) and running the economy for one period of production and trade. The ratio of average actual to optimal payoffs starts at about $20 \%$, and as the variance of prices falls, rises to about $55 \%$. 


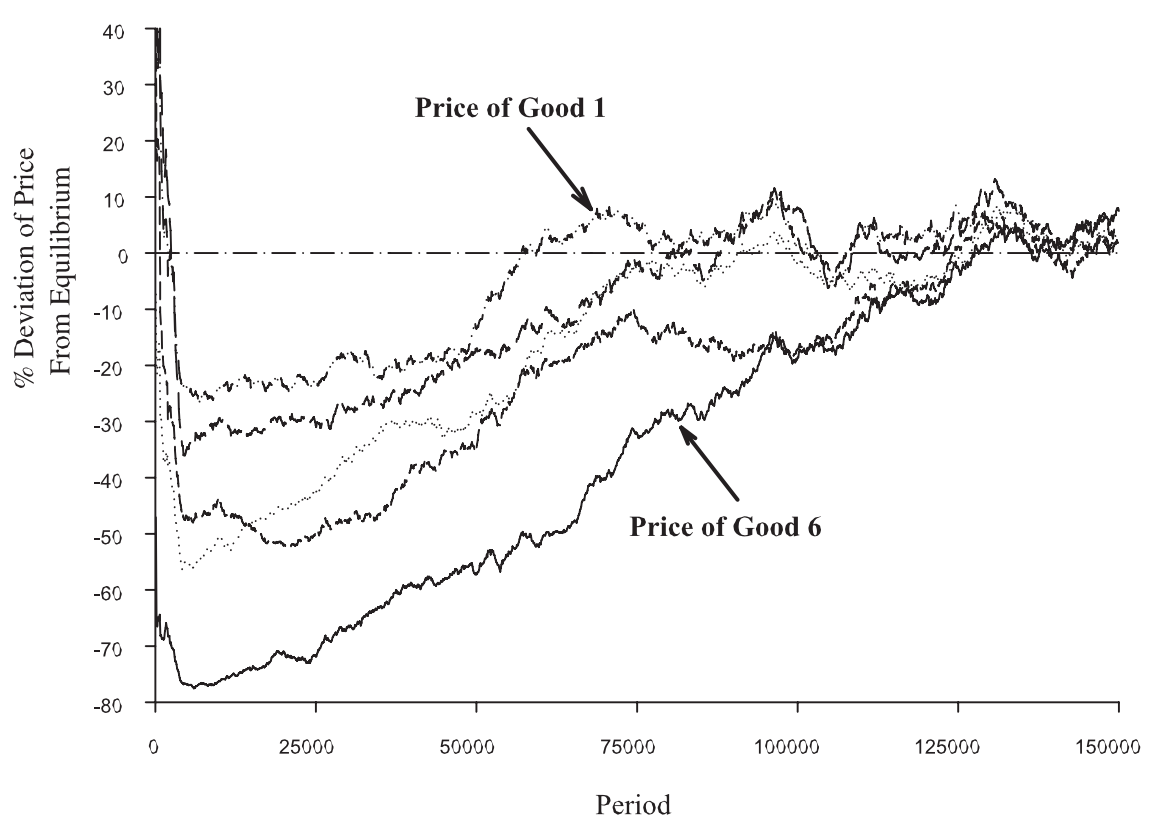

Figure 2: Long-Term Convergence of Quasi-Public prices to Quasi-Equilibrium (market-clearing) Prices. The three unlabeled schedules are the prices of the other three goods in a six sector model (one good is numeraire).

This strong movement of prices towards market equilibrium has nothing in common with the usual price adjustment mechanism in general equilibrium theory (Fisher 1983), in which prices changes are a function of aggregate excess supply. Rather, when a good is underpriced compared to its equilibrium price, a shopper who is willing to pay more and a seller who is willing to charge more will both do better, on average, than other agents whose private prices are nearer the reigning quasi-public price structure.

\section{Quasi-Walrasian Equilibrium when a Good is in Long-Run Excess Supply}

As a check on this argument, we alter the initial conditions so that good 1 is produced at half its previous rate, we assume there are three goods, and all other 


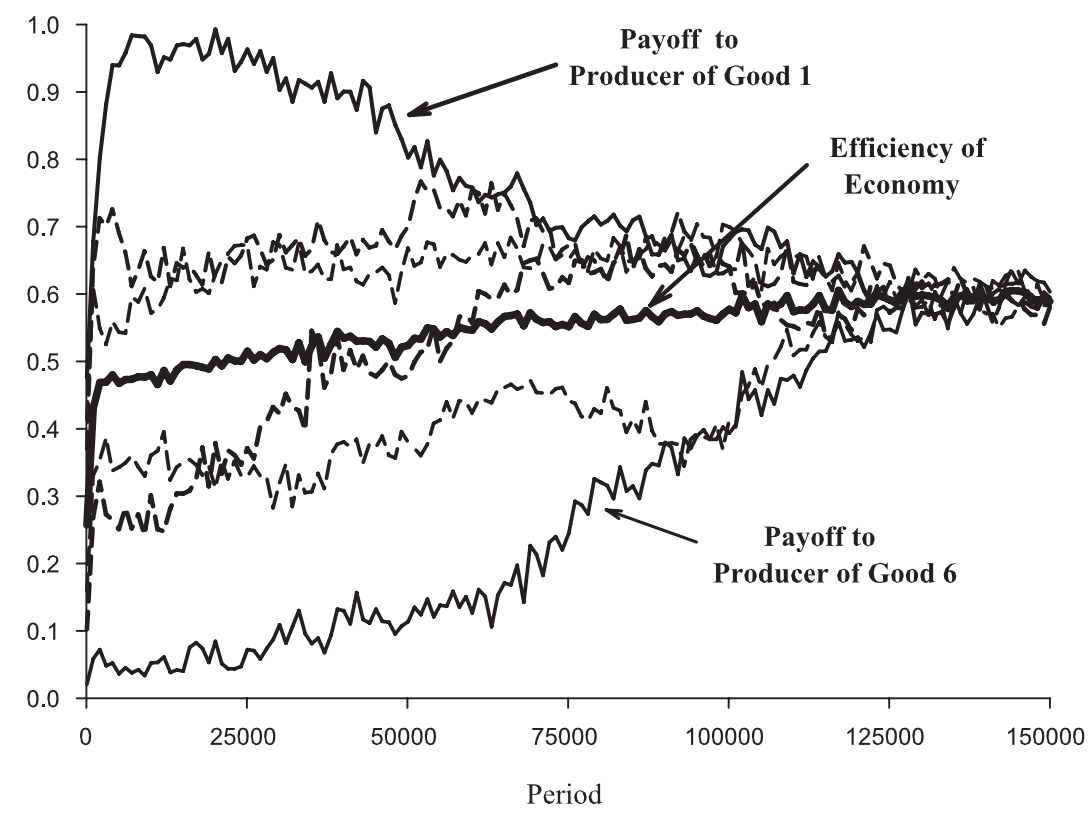

Figure 3: Long-Term Convergence of Payoffs to Quasi-Equilibrium Payoffs. The vertical axis gives payoffs as a fraction of full efficiency payoffs. The four unlabeled curves are the payoffs to the producers of the other four goods in the economy.

aspects of the simulation are the same as previously. There is thus an excess demand for good 1 in each period. Figure 4 shows the long-run movement of the relative payoffs of the producers of the three types of goods. In the long-run, the price of the goods in excess supply tends to zero, so all of the social product accrues to the producers of the good for which there is excess demand.

\section{The Effect of Flexible Supply Curves}

The preceding models assumed that the conditions of supply of each good are fixed. If we allow agents to switch from producing one good to another, we would expect that once quasi-public prices obtain, agents will shift production so that the returns to all producer types are roughly equal. This will lead to a disequilibrium in the size of the various production sectors. Then, as prices approach market equilibrium, the production sectors will approach their equilibrium size, which with the above parameters, is equal size for all sectors. Figure 5 shows that is in fact what occurs. 


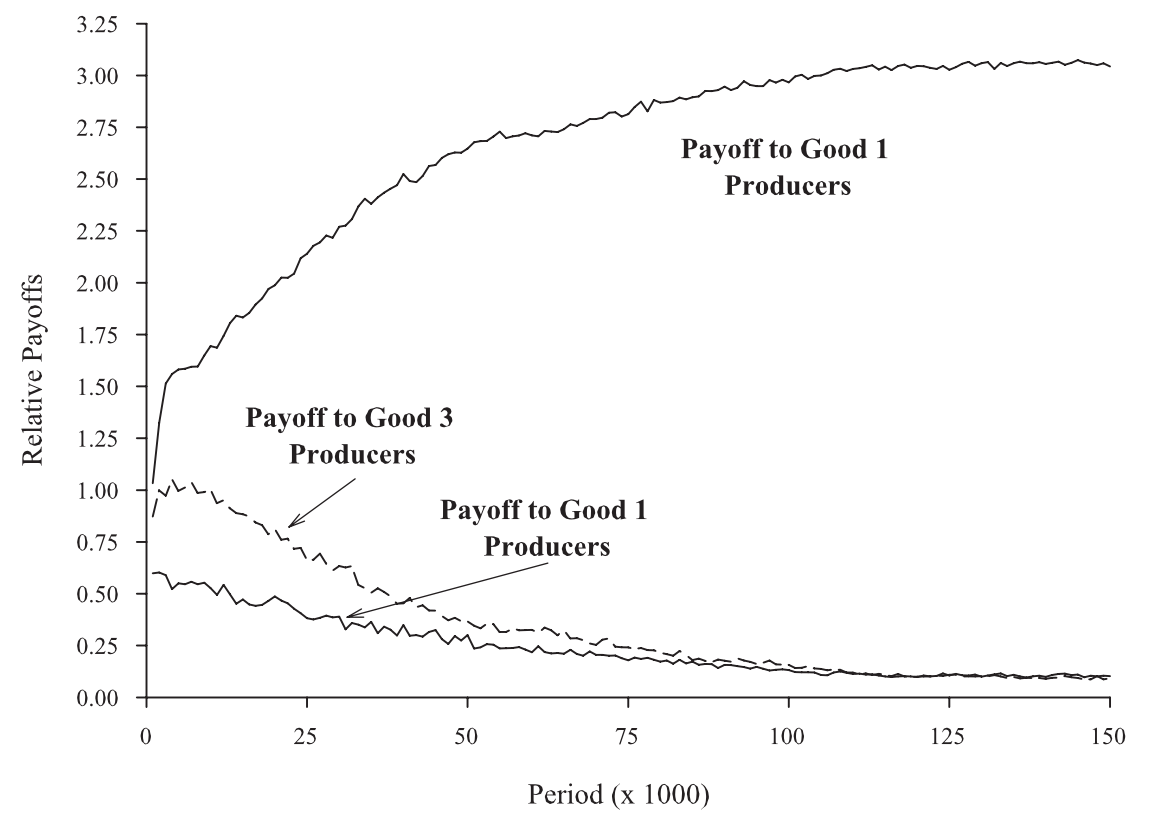

Figure 4: Convergence of Price to Zero when a Good is in Excess Supply. The figure shows that the payoffs to agents whose production good is in excess supply tends to zero. The economy has three goods.

In this run, only sectoral fractions of producers are shown. The movement of prices and payoffs is as previously described.

\section{Private Prices and Money}

Our results extend to a monetary economy. By money we mean an exchangeable good that is in fixed supply, being neither produced or consumed. Each agent is endowed with a share of the total money supply at the beginning of a simulation. We interpret the evolutionary dynamic as poorly performing agents dying and being replaced by copies of the well performing agents. An agent who reproduced inherits the money supply of the agent who died, and shares this equally with its offspring.

Agents now consider money the numeraire, so they continue to have $n$ private exchange ratios, this time for each good versus money. Each agent is given a 


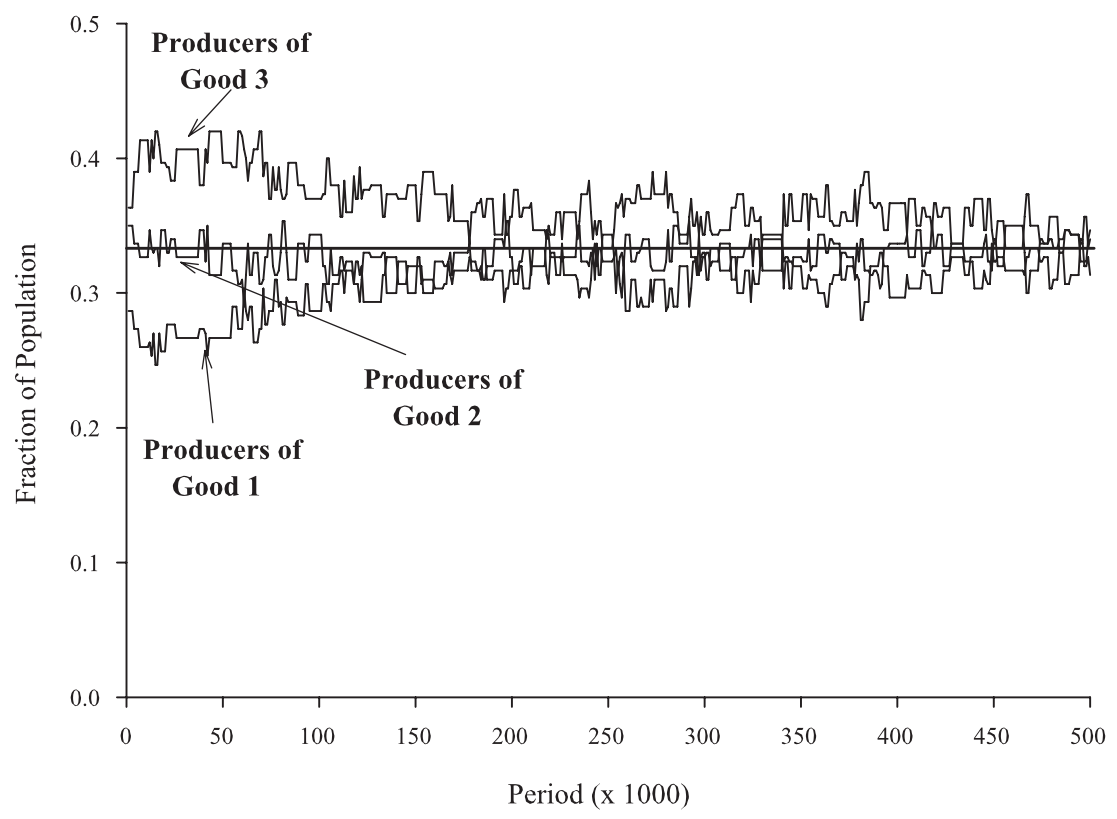

Figure 5: The Movement of Sectoral Shares when Supply is Flexible.

stock of 10 units of money at the start of the run. For this simulation we assume there are seven goods. of which each producer consumes three in each period. We choose $\left(o_{1}, \ldots, o_{7}\right)=(1,2,3,4,5,6,7)$, and an individual who produces good $i$ produces $k o_{i}$ units per period. In market equilibrium, prices are $p_{i}=$ $\left(1 / o_{1}, \ldots, 1 / o_{n}\right)$, a producer receives $k$ money units for his production good, and spends one money unit each on his $k$ consumption goods, receiving an amount $o_{c}$ of each consumption good $c$, so his consumption utility is unity. With these production conditions, supply equals demand in all markets, at least on average (since the consumption goods assigned agents in each period are randomly assigned, the law of large numbers applies). Figure 6 shows the evolution of the percent deviation of prices from market equilibrium prices, as well as the evolution of average payoffs for this monetary economy. Once again, we have long-term movement towards the market equilibrium levels, including nearly $90 \%$ efficiency towards the end of the simulation. 


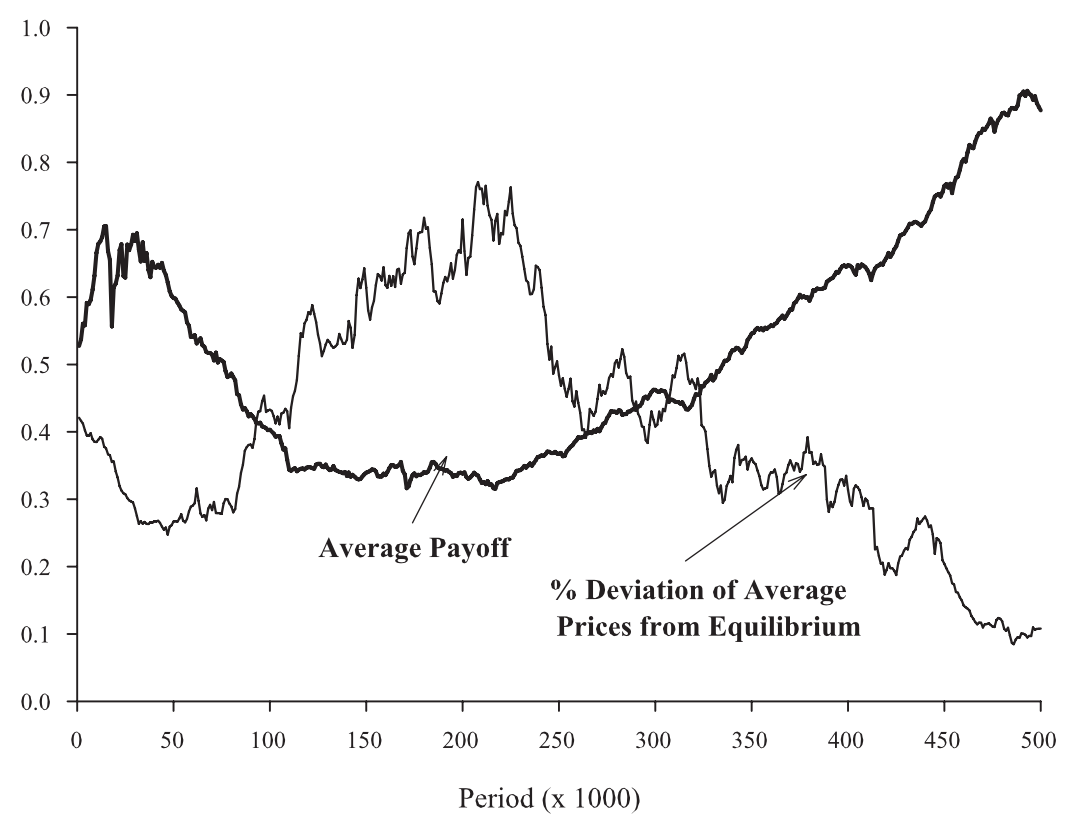

Figure 6: The Movement of Prices and Payoffs in a Monetary Economy. The Average Payoff schedule shows efficiency as compared with equilibrium public prices.

\section{Conclusion}

Our agent-based models of economic dynamics have revealed a fact that analytical models have systematically failed to recognize: the price system in a market economy has strong elements of a complex adaptive system, the evolution of which tends to stabilize a market economy. Public prices, by contrast, lead all agents to adjust in the same direction in a given period, thus creating a situation in which instability and chaos are likely outcomes.

We have shown that the informational requirements for a successful economic system are quite modest, and among the most important are the ability to ascertain the relative success of other agents, and the capacity to imitate the strategic behavior of the relatively successful.

The range of economies studied in this paper are extremely simple, without firms, raw materials, capital or intermediate goods, labor, or any of the many institutional characteristics of a real economy. In a companion paper, Gintis (2006) 
approaches the problem from the other direction, starting from a fairly complete implementation of a Walrasian general equilibrium model with public prices but no aggregate price adjustment mechanism, with results that are similar to those of this paper.

Our results should be considered empirical rather than theoretical: we have created a class of economies and investigated their properties for a range of parameters. It remains to develop analytical models of private pricing, the passage to quasi-public prices, and the subsequent passages to something akin to market clearing prices.

\section{REFERENCES}

Arrow, Kenneth J., "An Extension of the Basic Theorems of Classical Welfare Economics," in J. Neyman (ed.) Proceedings of the Second Berkeley Symposium on Mathematical Statistics and Probability (Berkeley: University of California Press, 1951) pp. 507-532.

- and Gerard Debreu, "Existence of an Equilibrium for a Competitive Economy," Econometrica 22,3 (1954):265-290.

Ausube, Lawrence M., Peter Crmton, and RAymond J. Deneckere, "Bargaining with Incomplete Information," in Robert Aumann and Sergiu Hart (eds.) Handbook of Game theory With Economic Implications, II (Amsterdam: North Holland, 2002) pp. 1897-1946.

Bala, V. and M. Majumdar, "Chaotic Tatonnement," Economic Theory 2 (1992):437-445.

Binmore, Ken and Maria Herrero, "Matching and Bargaining in Dynamic Markets," Review of Economic Studies 55 (1988):17-31.

Debreu, Gérard, Theory of Value (New York: Wiley, 1959).

Fisher, Franklin M., Disequilibrium Foundations of Equilibrium Economics (Cambridge, UK: Cambridge University Press, 1983).

Gale, Douglas, "Bargaining and Competition, Part I: Characterization," Econometrica 54,4 (July 1986):785-806.

Gintis, Herbert, "A Markov Model of Production, Trade, and Money: Theory and Artificial Life Simulation," Computational and Mathematical Organization Theory 3,1 (1997):19-41.

- , "The Dynamics of General Equilibrium," 2006. under resubmission, The Economic Journal.

Goldberg, David E., Genetic Algorithms in Search, Optimization, and Machine Learning (Reading, MA: Addison-Wesley, 1989). 
Holland, John H., Adaptation in Natural and Artificial Systems (Ann Arbor: University of Michigan Press, 1975).

Kunimoto, Takashi and Robert Serrano, "Bargaining and Competition Revisited," 2002. Brown University Working Paper 2002-14.

McLennan, Andrew and Hugo Sonnenschein, "Sequential Bargaining as a Non-Cooperative Foundation of Competitive Equilibrium," Econometrica 59 (1991):1395-1421.

Rubinstein, Ariel, "Perfect Equilibrium in a Bargaining Model," Econometrica 50 (1982):97-109.

- and Asher Wolinsky, "Equilibrium in a Market with Sequential Bargaining," Econometrica 53 (1985):1133-1150.

- and - ,"Decentralized Trading, Strategic Behavior and the Walrasian Outcome," Review of Economic Studies 57 (1990):63-78.

Saari, Donald, "Mathematical Complexity of Simple Economics," Notices of the American Mathematical Society 42,2 (February 1995):222-230.

Saari, Donald G., "Iterative Price Mechanisms," Econometrica 53 (1985):11171131.

Samuelson, Larry and Jianbo Zhang, "Evolutionary Stability in Asymmetric Games," Journal of Economic Theory 57,2 (1992):363-391.

Taylor, P. and L. Jonker, "Evolutionarily Stable Strategies and Game Dynamics," Mathematical Biosciences 40 (1978):145-156.

Tesfatsion, Leigh and Kenneth L. Judd, Handbook of Computational Economics II: Agent-Based Computational Economics (North-Holland, 2006).

Walras, Leon, Elements of Pure Economics (London: George Allen and Unwin, 1954 [1874]).

$c \backslash$ Papers $\backslash$ General Equilibrium $\backslash$ Simple Dynamics $\backslash$ Simple Dynamics of Market Exchange September 8, 2006 